\title{
Inhaled nitric oxide does not prevent postpneumonectomy pulmonary edema in pigs
}

\author{
Marc Filaire, MD, ${ }^{a}$ Elie Fadel, MD, ${ }^{\mathrm{b}}$ Benoît Decante, ${ }^{\mathrm{b}}$ Frédéric Seccatore, ${ }^{\mathrm{b}}$ Guy-Michel Mazmanian, MD, \\ and Philippe Hervé, $M D^{b}$
}

From CHU Clermont-Ferrand, Service de Chirurgie Générale et Thoracique, Hôpital Gabriel Montpied, and Université d'Auvergne, Laboratoire d'Anatomie, ${ }^{\mathrm{b}}$ Clermont-Ferrand, France; and the Experimental Surgery Laboratory and Department of Thoracic and Vascular Surgery and Heart-Lung transplantation, Centre Chirurgical Marie Lannelongue, ${ }^{\mathrm{b}}$ Paris-Sud University, Le PlessisRobinson, France.

Supported in part by AIR LIQUIDE SANTE.

Received for publication May 11, 2006; revisions received July 22, 2006; accepted for publication Sept 5, 2006.

Address for reprints: Philippe Hervé, MD, Centre Chirurgical Marie Lannelongue, Paris-Sud University, Le Plessis-Robinson, France (E-mail: pherve@ ccml.com).

J Thorac Cardiovasc Surg 2007;133:770-4

$0022-5223 / \$ 32.00$

Copyright (๑) 2007 by The American Association for Thoracic Surgery

doi:10.1016/j.jtcvs.2006.09.052
Objective: Increase in lung permeability is an inevitable consequence of pneumonectomy in relation to inflammatory injury and increased perfusion flow. We tested whether inhaled nitric oxide, a potent vasodilatator and anti-inflammatory agent, prevents postpneumonectomy edema in the first 24 hours after pneumonectomy in pigs.

Methods: We assessed hemodynamics, gas exchange, extravascular lung water estimated with the double-indicator dilution method, and lung neutrophil sequestration measured on the basis of lung myeloperoxidase activity at 1 and 24 hours after left pneumonectomy in 14 pigs randomly assigned to inhaled nitric oxide (10 $\mathrm{ppm})$ or control groups.

Results: Extravascular lung water content markedly increased at 1 and 24 hours after pneumonectomy, with no difference between the 2 groups. Hemodynamics did not differ between the 2 groups. Myeloperoxidase activity was higher and $\mathrm{PaO}_{2}$ values were lower in the nitric oxide group compared with in the control group.

Conclusions: Over the 24 hours after pneumonectomy, intraoperative inhaled nitric oxide levels neither improved gas exchange nor attenuated accumulation of lung water. On the contrary, they were associated with an increase in lung neutrophil sequestration and deterioration of arterial oxygenation, suggesting the occurrence of an early and toxic effect of nitric oxide.

$\mathrm{P}$ ostpneumonectomy pulmonary edema occurs in about $5 \%$ of patients undergoing pneumonectomy. ${ }^{1,2}$ Because the mortality rate can reach $75 \%$ to $100 \%,{ }^{3}$ prevention of this devastating complication is of extreme importance to improve surgical outcome. Increased lung permeability is an inevitable consequence of pneumonectomy. ${ }^{4}$ The principal mechanism involves inflammatory lung injury, as demonstrated in numerous experimental and clinical studies. ${ }^{4-7}$ Several additional factors might further aggravate this lung injury, including diminution of the lymphatic clearance because of associated lymphadenectomy, pre-existing lung injury after chemotherapy or radiotherapy, overdistention of the remaining lung, increased capillary hydrostatic pressure caused by enhanced perfusion flow, and perioperative fluid overload.

Inhaled nitric oxide $(\mathrm{NO})$ is a selective pulmonary vasodilatator ${ }^{8}$ and a potent pulmonary anti-inflammatory agent, as demonstrated by several experimental studies. $^{9-11}$ We therefore tested whether intraoperative inhaled NO might prevent postpneumonectomy lung edema. In the present study we investigated the effects of intraoperative inhaled NO on gas exchange, hemodynamics, lung neutrophil sequestration, and extravascular lung water (EVLW) during the first 24 hours after pneumonectomy in pigs.

\section{Materials and Methods}

Eighteen female pigs were studied (large white pigs; mean weight, $24 \pm 1.7 \mathrm{~kg}$ ). The study protocol was approved by the local ethics committee. All animals received humane care in 


\author{
Abbreviations and Acronyms \\ $\mathrm{CI}=$ cardiac index \\ EVLW = extravascular lung water \\ $\mathrm{FIO}_{2}=$ inspired oxygen fraction \\ MPAP $=$ mean pulmonary artery pressure \\ MPO = myeloperoxidase \\ MSAP $=$ mean systemic artery resistance \\ $\mathrm{NO}=$ nitric oxide \\ PBV = pulmonary blood volume \\ SVRI = indexed value of systemic vascular \\ resistance
}

compliance with the "Principles of laboratory animal care" formulated by the National Society for Medical Research and the "Guide for the care and use of laboratory animals" prepared by the Institute of Laboratory Animal Resources and published by the National Institute of Health (National Institutes of Health publication no. 86-23, revised 1985).

\section{Anesthesia and Mechanical Ventilation}

Animals were sedated with intramuscular ketamine $(100 \mathrm{mg} / \mathrm{kg})$ and anesthetized with intravenous pentobarbital $(10 \mathrm{mg} / \mathrm{kg})$, followed by a continuous intravenous infusion at $0.1 \mathrm{mg} \cdot \mathrm{kg}^{-1} \cdot \mathrm{min}^{-1}$, and paralyzed with pancuronium $(0.2 \mathrm{mg} / \mathrm{kg})$. The animals were intubated and mechanically ventilated (Servoventilator $900 \mathrm{D}$; Siemens Elema, Solna, Sweden) at a tidal volume of $10 \mathrm{~mL} / \mathrm{kg}$ and a respiratory rate of 20 cycles/min without positive end-expiratory pressure. The inspired oxygen fraction $\left(\mathrm{FIO}_{2}\right)$ was set to maintain a transcutaneous oxygen saturation of greater than 95\% (Solar $7000 \mathrm{SpO}_{2}$ module; Marquette Electronics, Milwaukee, Wis), and the respiratory rate was adjusted to obtain a $\mathrm{PaCO}_{2}$ value of between 35 and $45 \mathrm{~mm} \mathrm{Hg}$.

\section{Experimental Protocol}

Animals were randomly allocated to a 2-lung group $(n=4)$ or a pneumonectomy group $(\mathrm{n}=14)$. The 2-lung group was used as a control group for the potential effects of anesthesia and of 4-hour mechanical ventilation on lung permeability and EVLW content. In the pneumonectomy group animals were randomly allocated to a control $(n=7)$ or an NO $(n=7)$ group. Measurements were performed after 4 hours of ventilation in the double-lung group. Measurements were performed 1 hour (ie, approximately after 4 hours of ventilation and anesthesia) and 24 hours after pneumonectomy in the pneumonectomy groups.

\section{NO Administration}

NO, supplied as a mixture of NO (300 ppm) in nitrogen, was added to the breathing circuit to produce an inspired concentration of 10 ppm. NO was given for about 3 hours throughout the surgical procedure until wound closure. The concentration of NO in the inspired gas mixture was assessed by means of chemoluminescence (NOX-2000; Seres, Aix en Provence, France) from the inspiratory limb of the circuit.

\section{Left Pneumonectomy}

One-lung ventilation of the left lung was initiated at a tidal volume of $7 \mathrm{~mL} / \mathrm{kg}$ and a respiratory rate of 20 cycles/min without positive end-expiratory pressure. The $\mathrm{FIO}_{2}$ was set to maintain a transcutaneous oxygen saturation of greater than $95 \%$, and the respiratory rate was adjusted to obtain a $\mathrm{PaCO}_{2}$ value of between 35 and 45 $\mathrm{mm} \mathrm{Hg}$. The animal was positioned on the right side, and a left thoracotomy was performed. Pneumonectomy was started by ligating the pulmonary artery to avoid blood stagnation in the lung. Then the pulmonary veins and main bronchus were ligated. Once the thoracic wound had been closed, the pigs were laid down on their backs, and inhaled NO was stopped. A continuous infusion of $20 \mathrm{~mL} / \mathrm{kg}$ balanced electrolyte solution was administered for hydration during the operation. Then the animals were awakened and extubated. Twenty-four hours later, the pigs were anesthetized again and ventilated as previously described.

\section{Monitoring}

A 5F catheter was inserted into the left carotid artery for monitoring of systemic pressures and arterial blood gases. A pulmonary artery flow-directed Swan-Ganz catheter (Baxter Healthcare Corp, Edwards Division, Irvine, Calif) was inserted through the internal vein into the right pulmonary artery branch. Mean systemic artery pressure and pulmonary artery pressure were measured at endexpiration. Pulmonary artery occlusion pressure was obtained by means of intermittent inflation of the catheter balloon. Central venous pressure was measured through a catheter placed in the superior vena cava. A fiberoptic catheter (3F FT-Pulsiocath; Pulsion Medical Systems, München, Germany) was advanced under fluoroscopy into the descending aorta through the left carotid artery and was connected to a monitor (Cold Z-021, Pulsion Medical Systems). Intrathoracic blood volume, pulmonary blood volume (PBV), EVLW, and cardiac output were determined by using the thermal indocyanine green dye dilution method: $12 \mathrm{~mL}$ of a $5 \%$ glucose solution containing $2 \mathrm{mg} / \mathrm{mL}$ indocyanine green (Infracyanine; SERB, Paris, France) at between $0^{\circ} \mathrm{C}$ and $5^{\circ} \mathrm{C}$ was injected into the superior vena cava. Data provided correspond to the average of 3 measurements. Then cardiac index was calculated as cardiac output divided by body surface area. ${ }^{12}$ At the end of the experiment, the blood-free dry weight of each lung was determined, and PBV and EVLW were divided by the 2-lung dry weight in the 2-lung group or right lung dry weight in the pneumonectomy groups $\left(\mathrm{EVLW} / \mathrm{W}_{\mathrm{D}}\right.$ and $\left.\mathrm{PBV} / \mathrm{W}_{\mathrm{D}}\right)$ to adequately compare EVLW and $\mathrm{PBV}$ between each group. $\mathrm{PaO}_{2}$ and $\mathrm{PaCO}_{2}$ were measured with a blood gas analyzer (278-Blood Gas System; Corning, Medfield, Mass). The Swan-Ganz, venous, and carotid arterial catheters were connected to Solar 7000 transducers (Marquette Electronics). Mean systemic artery pressure, central venous pressure, and mean pulmonary artery pressure were continuously monitored. The pulmonary and systemic vascular resistance indexes (in dynes $\cdot \mathrm{sec} \cdot \mathrm{m}^{-2} \cdot \mathrm{cm}^{-5}$ ) were calculated as follows:

$$
\begin{aligned}
& \text { PVRI }=(M P A P / C I) 80 \\
& \text { SVRI }=(M S A P / C I) 80
\end{aligned}
$$

\section{Measurements}

All measurements were done after a stabilization period of 20 minutes at an $\mathrm{FIO}_{2}$ of 1.0. Hemodynamic variables, blood gas, 
TABLE 1. Characteristics of the double-lung group, control pneumonectomy group, and inhaled nitric oxide pneumonectomy group

\begin{tabular}{|c|c|c|c|c|c|}
\hline & \multirow{2}{*}{$\begin{array}{l}\text { Double-lung } \\
\qquad(n=4)\end{array}$} & \multicolumn{2}{|c|}{ Control pneumonectomy $(n=7)$} & \multicolumn{2}{|c|}{ NO pneumonectomy $(\mathrm{n}=7)$} \\
\hline & & H1 & H24 & H1 & H24 \\
\hline MPAP (mm Hg) & $10.2 \pm 1$ & $18.8 \pm 0.9^{*}$ & $12.8 \pm 0.6$ & $17.7 \pm 1.1^{*}$ & $13.5 \pm 0.9$ \\
\hline PAOP & $3 \pm 0.9$ & $6.1 \pm 0.9$ & $3.7 \pm 0.4$ & $6.8 \pm 0.9$ & $3.0 \pm 0.4$ \\
\hline $\mathrm{Cl}\left(\mathrm{L} \cdot \min ^{-1} \cdot \mathrm{m}^{-2}\right)$ & $4.37 \pm 0.54$ & $4.3 \pm 0.2$ & $2.7 \pm 0.1^{*} \dagger$ & $4.6 \pm 0.3$ & $2.8 \pm 0.1^{*} \dagger$ \\
\hline PVRI (dyne $\left.\cdot \mathrm{s} \cdot \mathrm{m}^{-2} \cdot \mathrm{cm}^{-5}\right)$ & $217 \pm 32$ & $239 \pm 26$ & $337 \pm 22^{*} \dagger$ & $188 \pm 18$ & $374 \pm 24^{*} \dagger$ \\
\hline $\operatorname{EVLWI}\left(\mathrm{mL} \cdot \mathrm{kg}^{-1}\right)$ & $5.7 \pm 0.78$ & $4.67 \pm 0.49$ & $5.29 \pm 0.40$ & $5.45 \pm 0.73$ & $5.84 \pm 0.84$ \\
\hline EVLW/W & 1.08 & $2.66^{*}$ & $2.92^{*}$ & $2.58^{*}$ & $2.86^{*}$ \\
\hline PBV/W & 1.99 & $4.04^{*}$ & $3.5^{*}$ & $3.98^{*}$ & $3.56^{*}$ \\
\hline $\mathrm{PaO}_{2}$ & $377 \pm 60$ & $335 \pm 53$ & $415 \pm 49 \dagger$ & $324 \pm 39$ & $354 \pm 48$ \\
\hline
\end{tabular}

$H 1$, One hour postoperatively; $H 24,24$ hours postoperatively; MPAP, mean pulmonary artery pressure; $P A O P$, pulmonary artery occlusion pressure; $C l$, cardiac index; $P V R I$, indexed value of pulmonary vascular resistance; $E V L W I$, indexed value of extravascular lung water; $E V L W / W_{D}$, extravascular lung water divided by the 2-lung dry weight in the 2-lung group or right lung dry weight in the pneumonectomy groups; $P B V / W_{D}$, pulmonary blood volume divided by the 2-lung dry weight in the 2-lung group or right lung dry weight in the pneumonectomy groups. $* P<.05$ versus double-lung group. $\dagger P<.05$ versus 1 hour postoperatively.

intrathoracic blood volume, and indexed values of PBV and EVLW were measured after 4 hours of ventilation in the 2-lung group and 1 hour (ie, approximately after 4 hours of ventilation) and 24 hours after pneumonectomy.

Lung myeloperoxidase (MPO) activity was measured as previously described ${ }^{13}$ in the resected left lung and in the right lung 24 hours after pneumonectomy. The baseline reference lung MPO activity was determined in a tissue specimen sampled from the lower part of the left lung soon after the thoracic incision. The postpneumonectomy lung MPO activity was determined in tissue specimens sampled from the lower part of the right lung 24 hours after the left pneumonectomy.

In addition, specimens were taken from the upper, middle, and lower parts of the right lung fixed in the formalin solution. All biopsy samples were examined in a blinded fashion by a pathologist.

\section{Statistical Analysis}

Data were computerized and analyzed with the Statview 5.0 software package for Windows (SAS, Cary, NC). Results were evaluated by using analysis of variance, followed by Fisher post-hoc tests. All values are reported as means \pm standard error of the mean.

\section{Results}

The 3 groups were comparable with respect to animal weight ( $20 \pm 0.5,24 \pm 1.8$, and $28 \pm 3.2 \mathrm{~kg}$, respectively) in the double-lung, NO pneumonectomy, and control pneumonectomy groups. Volume of intraoperative saline infusion was similar in both pneumonectomy groups $(621 \pm 46$ vs $765 \pm 103 \mathrm{~mL}$ in the $\mathrm{NO}$ and control pneumonectomy groups, respectively).

\section{Pulmonary Hemodynamic Values}

Data on pulmonary hemodynamic values are shown in Table 1. Preoperative hemodynamic values were similar in the 3 groups. Mean pulmonary artery pressure in- creased significantly at 1 hour after surgical intervention and returned to the preoperative level at 24 hours. The increase in mean pulmonary artery pressure at 1 hour after pneumonectomy was not associated with higher pulmonary artery occlusion pressure values, with no difference between each group.

\section{Lung Water Content and Gas Exchange}

Data on lung water content and gas exchange are shown in Table 1. EVLW/ $\mathrm{W}_{\mathrm{D}}$ and $\mathrm{PBV} / \mathrm{W}_{\mathrm{D}}$ were about 2 -fold higher after pneumonectomy compared with in the double-lung condition. Postpneumonectomy indexed values of EVLW were similar in the $\mathrm{NO}$ and control pneumonectomy groups, with no difference within each group between values at 1 or 24 hours after pneumonectomy. $\mathrm{PaO}_{2}$ values were comparable in the 2 pneumonectomy groups at 1 hour but decreased at 24 hours only in the NO pneumonectomy group.

\section{Lung MPO Activity}

Data on lung MPO activity are shown in Figure 1. In both pneumonectomy groups lung MPO activity was higher in the right lung 24 hours after pneumonectomy compared with values in the resected lung. MPO values in both the resected lung and the right lung 24 hours after pneumonectomy were higher in the animal receiving NO.

\section{Histology}

Severe edema and inflammatory infiltration were observed in the right lungs of 3 pigs of the NO pneumonectomy group and in 1 pig of the control pneumonectomy group. Microvascular thrombosis was observed in the lungs of 2 pigs of the pneumonectomy group and in 1 pig of the control pneumonectomy group. 


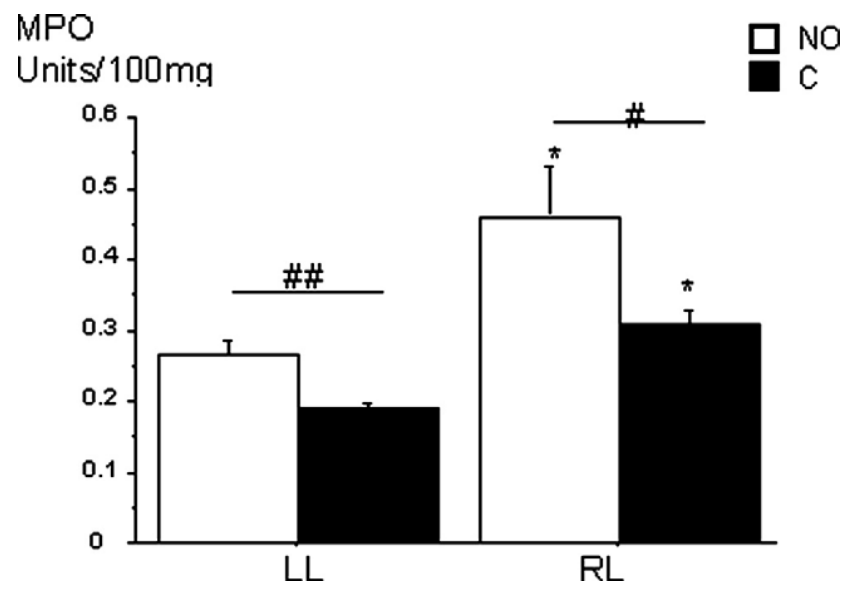

Figure 1. Lung myeloperoxidase activity in the resected left lung (LL) and in the remaining right lung (RL) 24 hours after pneumonectomy in the nitric oxide (NO) and control (C) groups. ${ }^{*} P<.05$ versus $L L$. $\# P<.05$, NO group versus control group. \#\# $P<.01$, NO group versus control group.

\section{Discussion}

In the present study we have tested the hypothesis that intraoperative inhaled NO might prevent postpneumonectomy edema in pigs. Contrary to our hypothesis, we found that inhaled NO was not able to prevent postpneumonectomy edema but was associated with increasing lung inflammation.

The accumulated EVLW after pneumonectomy, as an index of lung edema, was measured with the thermal indocyanine green dye dilution method. This double-indicator dilution method has been recently shown to accurately measure EVLW after pneumonectomy in human subjects ${ }^{14}$ and experimental animals. ${ }^{15}$ The measured EVLW and PBV values were divided by the 2-lung or right lung blood free dry weights $\left(E V L W / W_{D}\right)$, respectively, to reliably compare EVLW and PBV values in 2-lung animals and pneumonectomized animals. ${ }^{14}$ As expected, left pneumonectomy was associated with more than a 2-fold increase in EVLW/W in the remaining right lung, indicating that lung permeability was increased in our experimental model.

The consensus of the literature indicates that lung permeability increases after pneumonectomy. ${ }^{16}$ It might result from increased hydrostatic forces acting on the alveolocapillary membrane, from injury of the alveolocapillary membrane itself, or both. Increased pulmonary blood flow and volume in the remaining lung are inevitable consequences of pneumonectomy. However, because of the recruitment and distension of the pulmonary microvasculature, pulmonary artery occlusion pressure, an indicator of pulmonary capillary filtration pressure, was not significantly increased in our animals or in other studies. ${ }^{4,17}$ Thus increase in lung permeability after pneumonectomy was more likely related to direct injury of the alveolocapillary membrane. The mechanism of this lung injury remains unclear. Previous studies in human subjects ${ }^{4,5,7}$ and experimental animals ${ }^{6}$ indicate that oxidative damage and lung injury occur after pneumonectomy. Activation of neutrophils as a contributing cause of this lung injury was suggested by increases in blood concentrations of both neutrophil elastase and MPO after pneumonectomy. ${ }^{16}$ In agreement with this hypothesis, histologic examination and measurement of lung MPO activity demonstrate for the first time that recruitment and activation of neutrophils occur within the lung early after pneumonectomy.

Previous uncontrolled clinical studies have suggested that anti-inflammatory treatment with corticosteroids administered during surgical intervention might prevent postpneumonectomy edema ${ }^{18}$ and that inhaled NO could have potential benefits for patients with postpneumonectomy edema. ${ }^{19,20}$ Because inhaled NO is a potent and selective pulmonary anti-inflammatory agent, we hypothesized that prophylactic treatment with inhaled NO could be a safer alternative. Inhaled NO consistently prevents lung injury caused by oxidative stress and neutrophils in several experimental models, including ischemia and reperfusion, sepsis, and hyperoxia. ${ }^{9-11,21}$ NO interferes with neutrophil adherence to endothelium, inhibits platelet aggregation, and inhibits expression of several inflammatory mediators, including chemokines, interleukins, endothelin 1, and adhesion molecules. ${ }^{22-26}$ Contrasting with our hypothesis, postpneumonectomy edema was not prevented by inhaled NO. Moreover, the animals treated with inhaled NO had higher MPO activity and histologic inflammation in the remaining lung after pneumonectomy. This resulted in deterioration of arterial oxygenation in this group. These findings indicate that NO aggravates rather than improves lung inflammatory response after pneumonectomy. Interestingly, MPO value also increased in the resected lung after NO inhalation, whereas it remained within the normal range of values for our laboratory $^{27}$ in the control group. All these results are not so surprising considering that inhaled NO exhibits both proinflammatory and anti-inflammatory properties. ${ }^{28}$ The relative importance of the beneficial and toxic effects of $\mathrm{NO}$ is determined by the tissue concentration of NO, the concentrations of other reactive intermediates (including superoxide anion), and the presence of cellular antioxidants. When the NO concentration is high or sustained because of administration of exogenous $\mathrm{NO}$, cytotoxic reactive nitrogen intermediates, such as dinitrogen trioxide $\left(\mathrm{N}_{2} \mathrm{O}_{3}\right)$, can be formed. NO inflammatory toxicity can be also mediated by peroxynitrite, a highly reactive oxidant species formed by the rapid reaction of NO with superoxide anion. Because pneumonectomy favors the production of reactive oxygen species, ${ }^{6,7}$ inhaled NO could induce the production of various pro-oxidant NO metabolites and therefore aggravate lung inflammation. 
In summary, this study indicates that inhaled NO administered during surgical intervention does not decrease accumulation of EVLW after pneumonectomy and is associated with increased lung inflammation and worsening of gas exchange. This illustrates the dual effect of inhaled NO in potentiating or attenuating inflammation and oxidative damage in the lung as a function of its redo status. Thus inhaled NO cannot be recommended to prevent occurrence of postpneumonectomy lung edema in clinical practice.

We thank Mrs Martine Collomb for her help in the preparation of the manuscript.

\section{References}

1. Parquin F, Marchal M, Mehiri S, Hervé P, Lescot B. Postpneumonectomy pulmonary edema: analysis and risk factors. Eur J Cardiothorac Surg. 1996;10:929-33.

2. Verheijen-Breemhaar L, Bogaard JM, Van Deb Berg B, Hilvering C. Postpneumonectomy oedema. Thorax. 1988;43:323-6.

3. Van Der Werff, Van der Houwen HK, Heijmans PJM, Duurkens VA, Leusink HA, Van Heesewijk HP, et al. Postpneumonectomy pulmonary edema: a retrospective analysis of incidence and possible risk factors. Chest. 1997;111:1278-84.

4. Waller DA, Keavey P, Woodfine L, Dark JH. Pulmonary endothelial permeability changes after major lung resection. Ann Thorac Surg. 1996;61:1435-40.

5. Williams EA, Quinlan GJ, Goldstraw P, Gothard JWW, Ewans TW. Postoperative lung injury and oxidative damage in patients undergoing pulmonary resection. Eur Respir J. 1998;11:1028-34.

6. Williams E, Quinlan G, Anning P, Goldstraw P, Evans T. Lung injury following pulmonary resection in the isolated, blood perfused rat lung. Eur Respir J. 1999;14:745-50.

7. Lases EC, Vincent AMD, Wim BMG, Haas FJLM. Oxidative stress after lung resection therapy: a pilot study. Chest. 2000;117:999-1003.

8. Pepke-Zabba J, Higenbottam TW, Dinh-Xuan AT, Stone D, Wallwork J. Inhaled nitric oxide as a cause of selective pulmonary vasodilatation in pulmonary hypertension. Lancet. 1991;338:1173-4.

9. Barbotin-Larrieu F, Mazmanian M, Baudet B, Detruit H, Chapelier A, Libert JM, et al. Prevention of ischemia-reperfusion lung injury by inhaled nitric oxide in neonatal piglets. J Appl Physiol. 1996;80:782-8.

10. Bacha EA, Hervé P, Murakami S, Chapelier A, Mazmanian GM, de Montpreville V, et al. Lasting beneficial effect of short-term inhaled nitric oxide on graft function after lung transplantation. $J$ Thorac Cardiovasc Surg. 1996;112:590-8.

11. Razavi H, Werhun R, Scott JA, Weicker S, Wang LF, McCormack DG, et al. Effects of inhaled nitric oxide in a mouse model of sepsis-induced acute lung injury. Crit Care Med. 2002;30:868-73.

12. DuBois B, Dubois EF. A formula to estimate the approximate surface area if height and weight be known. Arch Intern Med. 1916;17:863-71.
13. Mullane KM, Kraemer R, Smith B. Myeloperoxydase activity as a quantitative assessment of neutrophil infiltration into ischemic myocardium. J Pharmacol Methods. 1985;14:157-67.

14. Schröder C, Kuhn K, Macchiarini P. Radical lymphadenectomy does not effect intrathoracic fluid volume changes after lung surgery. Internet J Thorac Cardiovasc Surg. 2005;vol. 7, No. 2.

15. Roch A, Michelet P, D'journo B, Brousse D, Blayac D, Lambert D, et al. Accuracy and limits of transpulmonary dilution methods in estimating extravascular lung water after pneumonectomy. Chest. 2005; 128:923-7.

16. Jordan S, Mitchell JA, Quinlan GJ, Goldstraw P, Evans TW. The pathogenesis of lung injury following lung resection. Eur Respir J. 2000;15:790-9.

17. Crouch JD, Lucas CL, Keagy BA, Wilcox BR, Ha B. The acute effects of pneumonectomy on pulmonary vascular impedance in the dog. Ann Thorac Surg. 1987;43:613-6.

18. Cerfolio RJ, Bryant AS, Thurber JS, Bass CS, Lell WA, Bartolucci AA. Intraoperative solumedrol helps prevent postpneumonectomy pulmonary edema. Ann Thorac Surg. 2003;76:1029-35.

19. Mathisen DJ, Kuo EY, Hahn C, Moncure AC, Wain JC, Grillo HC, et al. Inhaled nitric oxide for adult respiratory distress syndrome after pulmonary resection. Ann Thorac Surg. 1998;66:1894-902.

20. Rabkin DG, Sladen RN, DeMango A, Steinglass KM, Goldstein DJ. Nitric oxide for the treatment of postpneumonectomy pulmonary edema. Ann Thorac Surg. 2001;72:272-4.

21. Rovira I, Chen TY, Winkler M, Kawai N, Bloch KD, Zapol WM. Effects of inhaled nitric oxide on pulmonary hemodynamics and gas exchange in an ovine model of ARDS. J Appl Physiol. 1994;76: $345-55$.

22. Karamsetty MR, Klinger JR. NO: no more than just a vasodilatator in lung transplantation. Am J Respir Cell Mol Biol. 2002;26:1-5.

23. Mimamoto K, Pinsky DJ, Fujita T, Naka Y. Timing of nitric oxide donor supplementation determines endotheline-1 regulation and quality of lung preservation for transplantation. Am J Respir Cell Mol Biol. 2002;26:14-21.

24. Guidot DM, Hybertson BM, Kitlowski RP, Repine JE. Inhaled NO prevents IL-1 induced neutrophil accumulation and associated acute edema in isolated rat lungs. Am J Physiol Lung Cell Mol Physiol. 1996;271:L225-9.

25. Lefer DJ, Jones SP, Girod WG, Baines A, Grisham MB, Cockrell AS, et al. Leucocyte-endothelial cell interactions in nitric oxide synthetasedeficient mice. Am J Physiol Heart Circ Physiol. 1999;276:H1943-50.

26. Lindermann S, Sharafi M, Spieker M, Buerke M, Fisch A, Grosser T, et al. NO reduces PMN adhesion to human vascular cells due to down regulation of ICAM-1 mRNA and surface expression. Thromb Res. 2000;97:113-23.

27. Fadel E, Mazmanian GM, Chapelier A, Baudet B, Détruit H, de Montpreville V, et al. Lung reperfusion injury after chronic or acute unilateral pulmonary artery occlusion. Am J Respir Crit Care Med. 1998;157:1294-300.

28. Weinberger B, Laskin DL, Heck DE, Laskin JD. The toxicology of inhaled NO. Toxicol Sci. 2001;59:5-16. 